\title{
How They Want It: A Study On Chinese Students' Preferred Learning Methods
}

Deniss Yeung, Waikato Institute of Technology, New Zealand

Fred Fu (Jianbo), Chengdu University, People's Republic of China

\begin{abstract}
This paper discusses the preferred study methods of Chinese students based on the research findings involving Chinese students studying in the School of Business, Wintec. In order to provide relevant academic delivery, quality education and to maintain sustainability in the international market, New Zealand education institutes have to understand Chinese students' background, behaviour and learning difficulties while they are studying in New Zealand.
\end{abstract}

Keywords: international students; study methods

\section{INTRODUCTION}

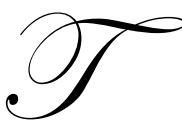

his study was prompted by one institution's decision to make quality, student-centeredness and internationalisation a strategic priority. Through existing relationships with several institutes in China, it has been possible to gauge their students' preferred learning methods. However, on quick review of the literature, it became apparent that there is a dearth of research on Chinese students' preferred learning methods while they are studying overseas. The researchers set out to redress this imbalance and from the insights gained, put forward recommendations to strengthen quality academic delivery and staff training. The findings provide practical suggestions for institutes that want to provide quality teaching, relevant student service to international students, and to grow in the international marketplace.

\section{BACKGROUND}

\section{New Zealand Tertiary Education Export Situation}

International students have been providing both monetary and other benefits to the New Zealand education sector. In 2009, more than 93,000 foreign students studied in New Zealand, earning the country $\$ 2.3$ billion and making education one of New Zealand's biggest export earners (Education New Zealand, 2010). Of these international students, more than 20,000 were from China.

\section{Chinese School Class Organisation}

Chinese students, in the past, and in many cases today, are grouped into classes with no concern for ability and the grouping may remain relatively stable from lower grades through to university level education (Littrell 2010). A tradition in this environment is for the better students in the class to tutor and help the weaker students. This could include assisting the weaker students during examinations at the university.

This kind of behaviour may be treated as cheating and plagiarism in Western education institutes, including those in New Zealand; however, Chinese students may see it as group work.

\section{English Learning Skills}

English language education in Chinese schools is organised into separate "Speaking", "Listening", "Reading", and "Writing" classes. In Writing and Reading classes, the students may never hear the language spoken. 
Much of the oral training is rote memorization (Duan, 2003).

Due to the lack of practice, when Chinese students enter a Western classroom, most of them will find it difficult, if not impossible, to catch up with lectures and to communicate with domestic students.

\section{Wintec's Strategic Priorities}

In order to remain financially sustainable and grow, Wintec has set a number of strategic priorities. The strategic priorities relevant to this study are Academic Delivery and Internationalisation.

Academic Delivery

In order to deliver programmes that are relevant and meet the needs of students, Wintec's strategic priorities include the provision of high levels of student satisfaction and completion rates, with nationally and internationally recognised levels of quality.

\section{Internationalisation}

Internationalisation and collaboration with international partners is a cornerstone of Wintec's development plans. As more countries want their students to remain at home for tertiary study, the development of Wintec programmes delivered overseas is seen as an important strategy.

Recently there have been several projects in China between Wintec and Chinese institutes to offer Pathway programmes in different schools at Wintec. Students in China have the opportunity to spend one or two years at home, then another one or two years at Wintec, to gain a Wintec qualification. This arrangement has been popular and the number of Chinese students has been growing since 2007.

\section{PURPOSE AND OBJECTIVES OF THE STUDY}

Based on the analysis of Chinese students' background, behaviours and their English skills mentioned above, plus the growing number of Chinese students at Wintec, the researchers want to comprehend Chinese students' preferred learning methods and the underlying reasons for their preferences. Research findings will then be shared with Wintec academic staff to enable suitable and relevant academic delivery, so as to contribute to Wintec's quality academic delivery and internationalisation strategies.

Specific objectives of the research are:

1. to ascertain Wintec Chinese students' preferred learning methods

2. $\quad$ to establish the underlying reasons of their preference

3. to recommend relevant and suitable academic delivery strategies for quality teaching

\section{METHODOLOGY}

\section{Respondents}

Stage One

Ten Chinese students from partnered Chinese institutes studying on a full-time degree programme at the School of Business, Wintec, were invited to a focus group meeting.

Stage Two

Sixty four self-directed questionnaires were distributed to six Wintec business classes during class time. The researchers explained the background and purpose of the study and Chinese students were invited to complete the questionnaire. 


\section{Questionnaire}

Stage One

As well as demographic information, the following questions were asked (Appendix I):

Question 1: Which aspects in your learning at Wintec are different from in China?

Question 2: What are your preferred study methods at Wintec?

Question 3: Could you please rank your preferred study methods?

Question 4: What are the reasons of your preferred study methods at Wintec?

Question 5: Could you please rank your reasons of your preferred study methods at Wintec?

Question 6: What are your learning problems at Wintec?

Stage Two

In addition to the demographic questions, ten questions were designed by the researchers and the Perceptual Learning-Style Preference Questionnaire was adopted in this part of the research. (Appendix II).

\section{Procedure}

In mid-September 2009, the focus group questionnaire was drafted and reviewed by the staff of School of Business to confirm the validity of questions. A focus group meeting was carried out at Wintec with ten Chinese students and audio recordings were made.

After the analysis of the focus group results, the survey questionnaire was drafted, and in late September, 64 questionnaires were distributed to six Wintec business classes. Of the 64 returned surveys, 56 were valid.

\section{Data Entry and Analysis}

Data from returned questionnaires were entered into the computer using Microsoft Excel software which could generate graphs for viewing and presentation.

Graphs generated by Microsoft Excel were transferred to Microsoft Word for report writing purposes.

\section{Compliance with Protocols for Research}

The processes and procedures used in this research followed the Protocols/Principles for Conducting Research in a Maori Context developed by The Waikato Institute of Technology (Wintec, 2006) and also abided by the Human Ethics in Research protocols.

\section{RESULTS}

Sixty-four survey questionnaires were distributed to students at the School of Business, Wintec; all were completed, giving a response rate of $100 \%$. Of the 64 returned questionnaires, 56 were valid.

The present study sets out to ascertain Chinese students' preferred study methods and the underlying factors of their preferences. It is believed that the insights gained will contribute to a better understanding of Chinese students' backgrounds, behaviours and preferences, and that these findings will act as a catalyst for strengthening a strategic commitment that has been made to advancing the effectiveness of Quality Delivery and Internationalisation. 
Figure 1: Gender

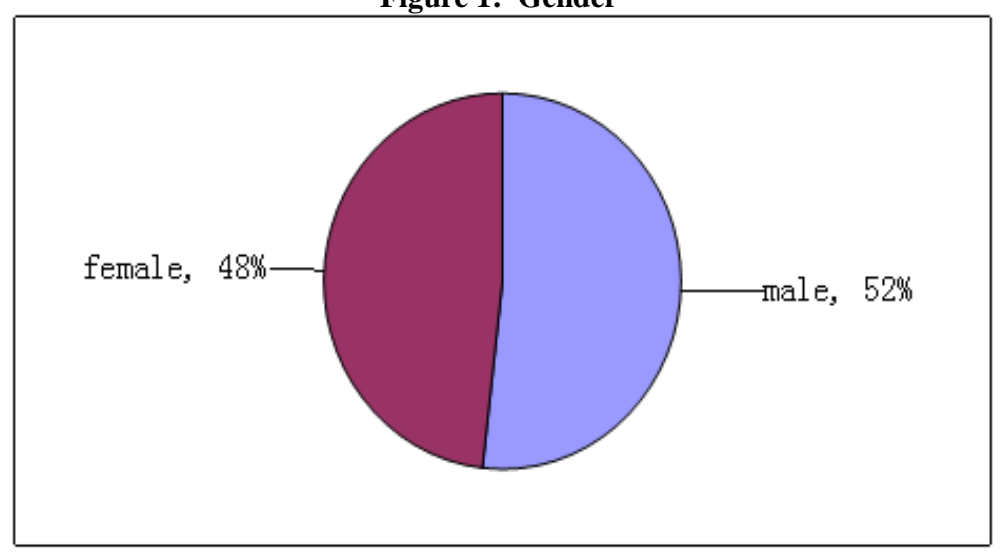

Figure 1 shows that just over half of the respondents (52\%) were male and $48 \%$ were female.

Figure 2: Age

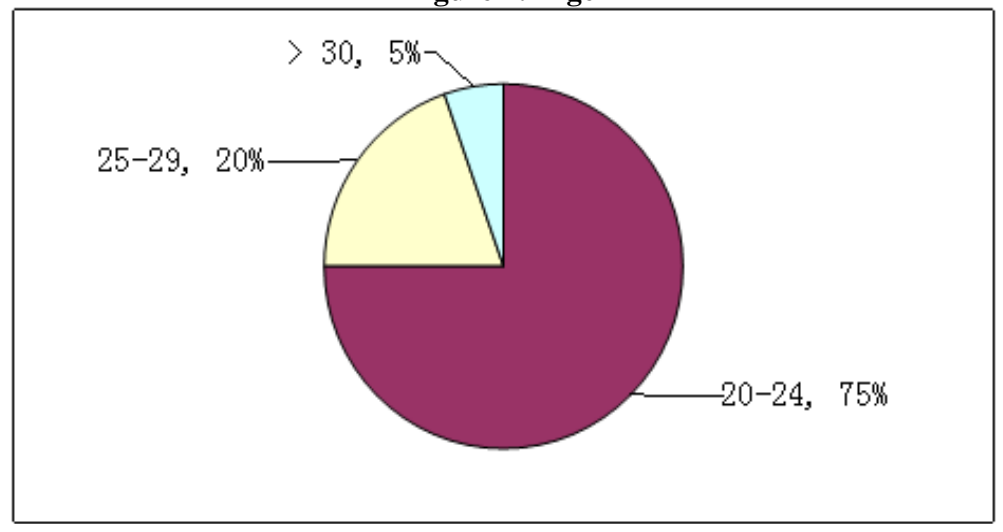

Figure 2 shows that most respondents (75\%) were between the ages of 20 and 24 and $20 \%$ were between 25 and 29. The rest of the students $(5 \%)$ were over 30 years of age.

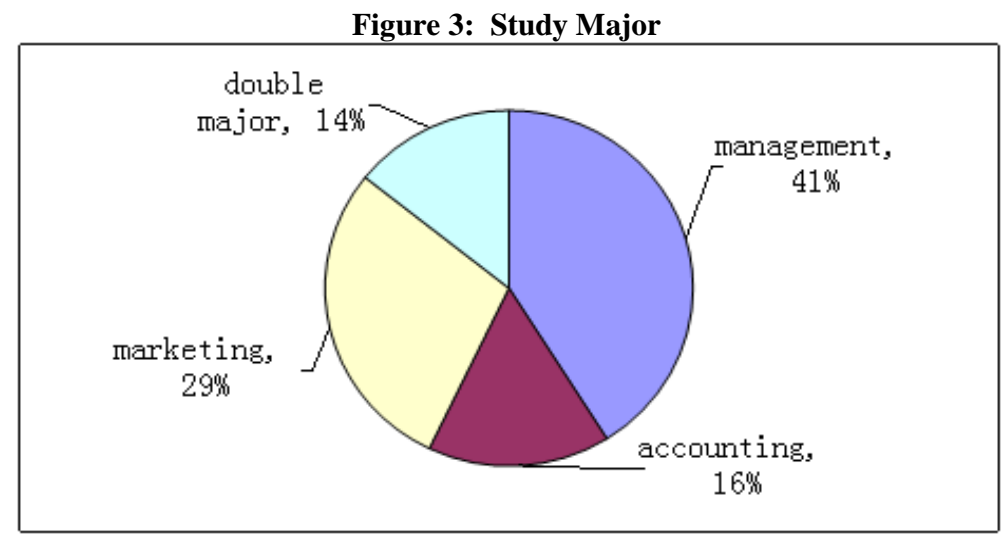

Figure 3 shows that most students involved in the research $(41 \%)$ were majoring in management, followed by marketing $(29 \%)$ and accounting $(16 \%)$. Fourteen percent of the students were doing a double major. 
Figure 4: Length of Time in New Zealand

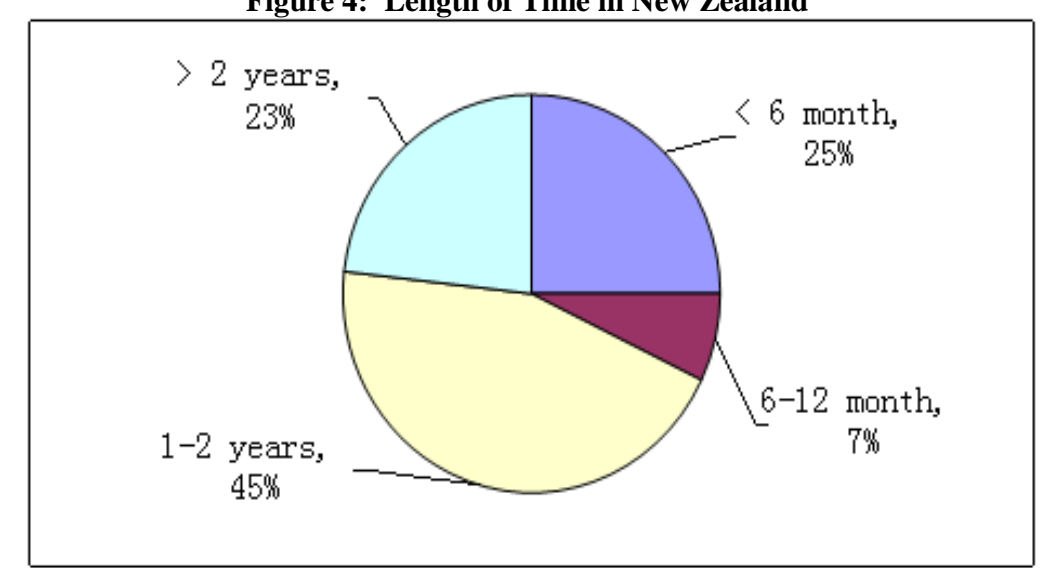

As seen in Figure 4, a high number of students (45\%) had been in New Zealand between one to two years, followed by $25 \%$ having been in NZ for less than six months. Under a quarter $(23 \%)$ of the respondents had been in New Zealand for more than two years. The rest of the students $(7 \%)$ said they had been in New Zealand between six months to one year.

Figure 5: Learning Experience

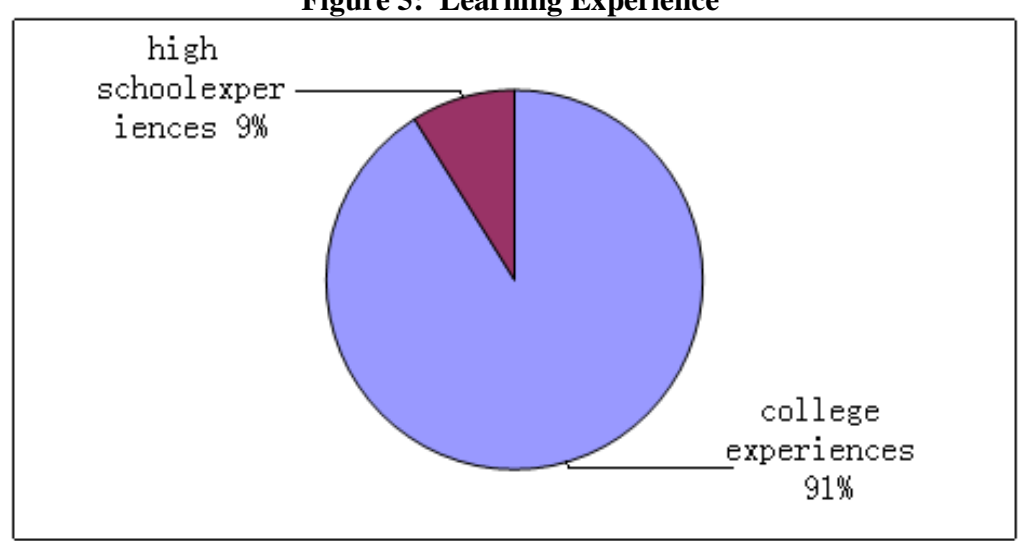

Figure 5 shows that the majority $(91 \%)$ of the respondents had college experience before they came to Wintec and $9 \%$ had high school experience when they arrived in New Zealand.

Figure 6: Work Experience in New Zealand

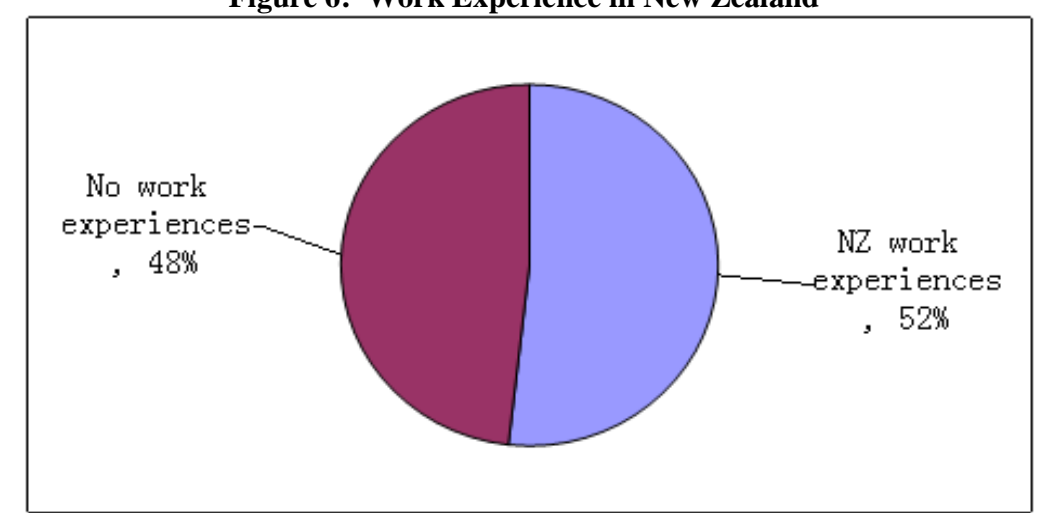

Figure 6 indicates that just over half of the respondents $(52 \%)$ had work experience in New Zealand. 
Figure 7: Preferred Study Methods

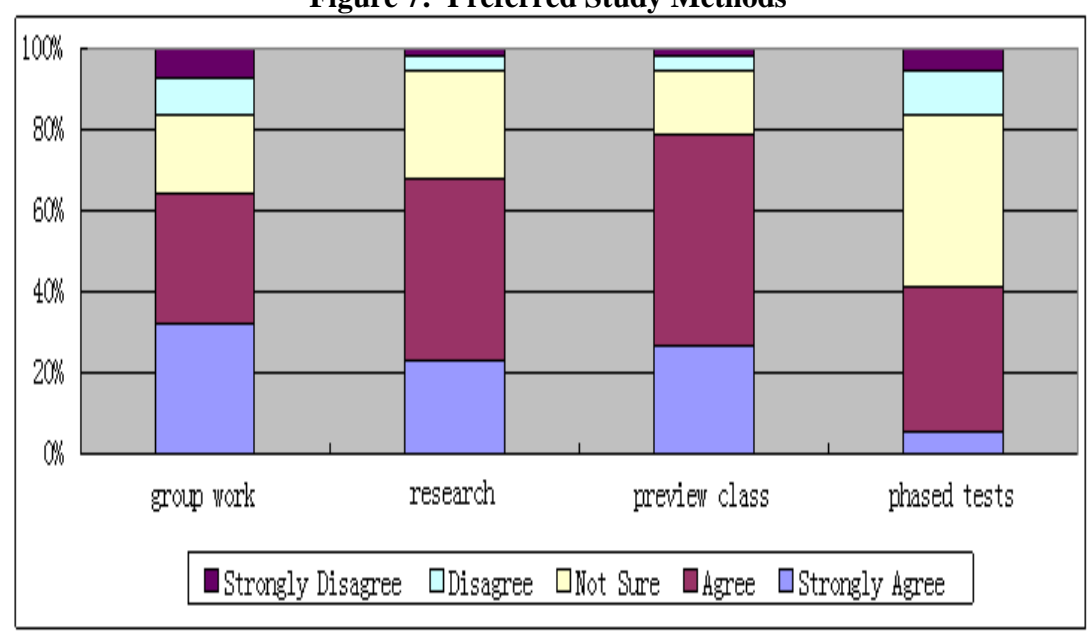

As shown in Figure 7, more than $60 \%$ of respondents indicated that group work, research and preview class materials were their preferred study methods. Close to $60 \%$ of the respondents said that phased tests were not their preferred study method.

Figure 8: Factors Affecting Preferred Study Methods

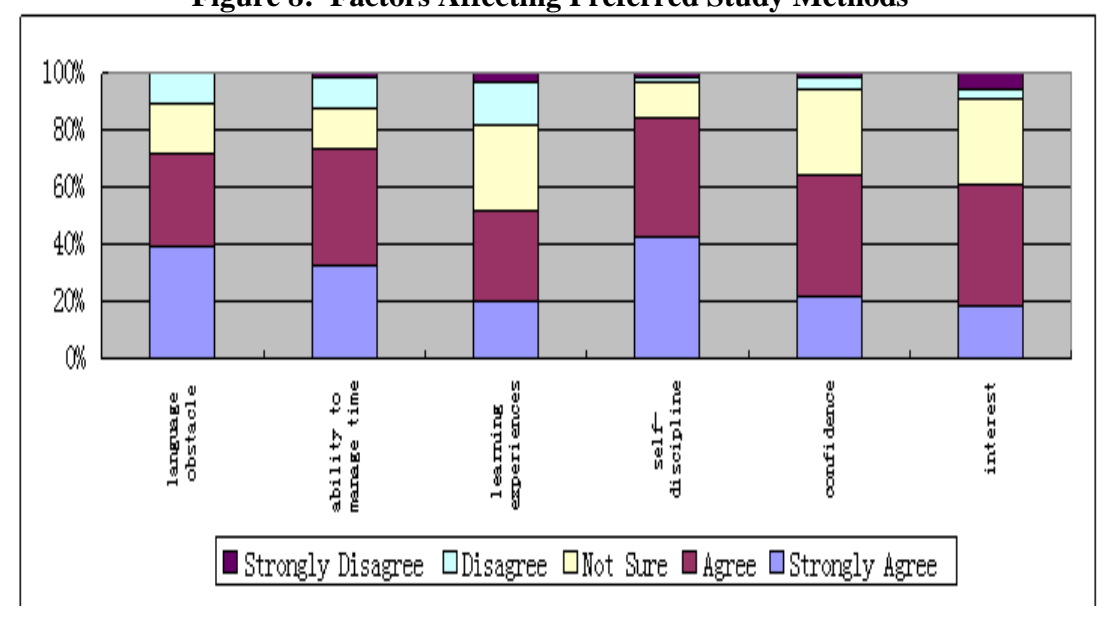

Figure 8 shows that more than $80 \%$ of respondents strongly agreed/agreed that self-discipline was a main factor of their preferred study methods. More than $70 \%$ of the respondents indicated that language obstacles and time management were the next major factors, followed by confidence and interest (over 60\%). Around 50\% said that the learning experience in China was not an important factor.

\section{LIMITATIONS}

The present research sample size is small (64) compared to the potential number of students from China. Respondents were from two Chinese institutes (Shengdong University of Technology and Sanjiang University). A larger sample size is needed to draw a better conclusion.

The questionnaire used was in English and it is believed that a Chinese version of the questionnaire might generate better responses and answers. 


\section{CONCLUSIONS AND RECOMMENDATIONS}

\section{Conclusions}

To be more competitive in the world market, it is important for education institutes to understand international students' backgrounds and issues so as to provide satisfactory education services.

The findings of this study provide useful insights into Chinese students' preferred study methods and the reasons affecting their preferences.

Chinese students preferred to study in groups, in particular, under a new study environment and where there was language difficulty. They also preferred doing research work and previewing course materials before class.

Most Chinese students agreed that the main factors contributing to their study preferences were language obstacles, time management, self-discipline, confidence of learning and interest. In particular, lack of confidence was the major factor in research work.

\section{Recommendations}

Educational institutes that want to offer better education quality to Chinese students need to understand the background, behaviour and expectations of these students and provide suitable methods and styles of delivery.

The findings of this study suggest institutes need to provide course materials for Chinese students before class. Those materials could be in print format or put online to increase efficiency and flexibility, since the Chinese students are now familiar with online learning because the Chinese government has been encouraging online learning solutions (Levy, 2003). Given the existing and future development of computing and internet technology, plus the high costs of studying overseas, students are ready to choose those institutes that can provide flexible, mixed mode delivery and cost effective courses for them (Yeung, 2008).

Additional help or tutorials should be provided for Chinese students if there is research work involved because most Chinese students do not possess such experience during their high school or even college study.

Well structured courses and programmes, with appropriate time schedules, are recommended to address the time management and self-discipline issues.

Further research with larger sample sizes and surveying students from other parts of China are recommended so that comparative study and better conclusions can be obtained.

\section{REFERENCES}

1. Duan, X-R. (2003). Chinese higher education enters a new era. Academe, 89, No. 6, 22.

2. $\quad$ Education New Zealand. 2010, July 20

3. Keele University, (2005 August). Common Difficulties for International Students. Retrieved from Keele University (5 July 2009), Student Support Division website http://www.keele.ac.uk/depts/aa/studentsupport/counselling/intproblems.htm

4. Levy, J. (2003). The next China: revolution - online learning boom in China.

5. Littrell, R. F. (2010) Learning styles of students in and from Confucian cultures. Retrieved from http://romielittrellpubs.homestead.com/files/littrell_eu_asean_crossculturallearningstyles.pdf (27 August 2009)

6. Reid, J. (2009) Perceptual Learning-Style Preference Questionnaire (9 September 2009) http://lookingahead.heinle.com/filing/l-styles.htm 
7. Wintec (2006, February). Waikato Institute of Technology. Human Ethics in Research Policy Conducting Research Involving WINTEC Staff and/or Students Protocols/Principles for Conducting Research in a Maori Context (14 September 2009) (https://staff.wintec.ac.nz/NR/rdonlyres/84A0A540-38A3-4DCC80A5-F8475AD9BFFD/0/ConductResearch_PartA.pdf)

8. Wintec (2010, July). Wintec strategic priorities. (Retrieved 28 June 2010). https://staff.wintec.ac.nz/NR/rdonlyres/5C998E9E-0D57-45ED-8097B7A44B399912/0/OurDirectionMay2009.pdf

9. Yeung, D. (2008). E-Learning Preferences of International Students: The Shandong University of Technology Study (SDUT). Journal of College Teaching \& Learning - April 2008, p. 63-70. 


\section{APPENDIX I}

\section{QUESTIONS FOR FOCUS GROUP MEETING}

Researchers will ask the questions and answers will be written on board to stimulate further responses. The meeting will be audio taped for record and analysis purposes.

\section{$\underline{\text { Part } 1}$}

The first part of questions is made up of easy questions as a warm-up for participants.

Question 1: What's your major? $\quad$ Management $\quad$ Marketing Accounting

Question 2: How long have you been New Zealand? <1 year 1--2 years >2 years

Question 3: Did you have any college learning experiences in China before you came to New Zealand?

$$
\text { Yes No }
$$

Question 4: Do you have any job experiences when you are learning in New Zealand? How long?

$$
\text { Yes No }
$$

Question 5: Your gender?

$$
\mathrm{M} \quad \mathrm{F}
$$

Question 6: Your age?

$<20 \quad 21-24 \quad>25$

\section{$\underline{\text { Part } 2}$}

The middle part of questions is made up of some open questions to describe the situation of students.

Question 7: Which aspects in your learning at Wintec are different from in China?

Question 8: What are your preferences of learning style at Wintec, including class organizing, assessment, assignment, environment, group work, research, etc?

Question 9: What are the related factors to your preferences of learning at Wintec?

Question 10: What are the problems in your learning experiences at Wintec?

Question 11: What are suggestions for future students before they come to NZ?

\section{$\underline{\text { Part } 3}$}

The final part of questions is made up of some supplement to confirm the above information.

Question 12: Could you please rank the importance of your preference about the learning styles above?

Question 13: Could you please rank the importance of your preference about the affective factors above to your learning styles?

Question 14: Do you have any other things to express? 


\section{APPENDIX II}

\section{SURVEY QUESTIONNAIRE}

\section{Questionnaire for Learning Preferences Research}

Thank you for completing this questionnaire. The purpose of the questionnaire is to analyse Chinese students' learning preferences as well as the causing factors, and to provide some suggestions to School of Business. Part A (Questions 1 to 6) is on background information. Please circle your choices.

\section{$\underline{\operatorname{Part} \mathbf{A}}$}

1. What is your Major?
(1) Management
(2) Accounting
(3) Marketing

2. How long have you been in New Zealand?
(1) Less than 6 months
(2) 6 months to 1 year
(3) 1 to 2 years
(4) More than 2 years

3. Did you have any college experiences in China before you came to New Zealand?

(1) Yes

(2) No

4a. Do you have any work experiences in New Zealand?

(1) Yes (2) No (Skip to question 5)

4b. How long have you been working in New Zealand?

(1) Less than 6 months (2) 6 months to 1 year (3) 1 to 2 years (4) More than 2 years

5. Your gender?
(1) Male
(2) Female

6. Your age?
(1) Under 20
(2) 20-24
(3) $25-29$
(4) 30 and more 


\section{$\underline{\text { Part B }}$}

This part (question 7 to 10) describes some preferences of learning. Decide whether you agree or disagree with each statement. Please respond to each statement quickly, without too much thought. Try not to change your responses after you choose them. Please answer all the questions. Please circle your choices. Thank you.

\begin{tabular}{|c|c|c|c|c|c|c|}
\hline \multicolumn{2}{|l|}{ Item } & \multicolumn{2}{|c|}{ 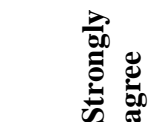 } & \multicolumn{2}{|c|}{ 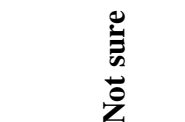 } & \multirow{2}{*}{ 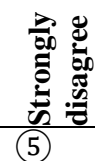 } \\
\hline $7-1$. & I prefer to do group assignments in my learning & (1) & $(2)$ & (3) & (4) & \\
\hline $7-2$ & I prefer to do some research in my assignments, reports and classes etc. & (1) & $(2)$ & (3) & (4) & $(5)$ \\
\hline $7-3$. & $\begin{array}{l}\text { I prefer to preview my class materials, including looking up ppt, } \\
\text { collecting some background information, special terms etc. }\end{array}$ & (1) & (2) & (3) & (4) & (5) \\
\hline 8 . & I prefer phased tests to assess my progress in my learning. & (1) & $(2)$ & (3) & $(4)$ & (5) \\
\hline $9-1$. & Language problem is the biggest obstacle during my learning. & (1) & (2) & (3) & (4) & (5) \\
\hline $9-2$. & The ability to manage time is an important factor in my learning. & (1) & $(2)$ & (3) & (4) & $(5)$ \\
\hline $9-3$ & My past learning experience in China influences my learning outcomes. & (1) & $(2)$ & (3) & (4) & (5) \\
\hline $9-4$. & Attitude/Self-discipline is an important factor in my learning. & (1) & (2) & (3) & (4) & (5) \\
\hline $9-5$. & Confidence of learning affects my learning deeply. & (1) & (2) & (3) & (4) & (5) \\
\hline 9-6. & I am interested in my major. & (1) & $(2)$ & (3) & (4) & (5) \\
\hline $10-1$. & When the teacher tells me the instructions I understand better. & (1) & $(2)$ & (3) & (4) & (5) \\
\hline $10-2$. & I prefer to learn by doing something in class. & (1) & (2) & (3) & (4) & (5) \\
\hline $10-3$. & I get more work done when I work with others. & (1) & $(2)$ & (3) & (4) & (5) \\
\hline $10-4$. & I learn more when I study with a group. & (1) & $(2)$ & (3) & (4) & (5) \\
\hline $10-5$. & In class, I learn best when I work with others. & (1) & $(2)$ & (3) & (4) & (5) \\
\hline $10-6$. & I learn better by reading what the teacher writes on the chalkboard. & (1) & (2) & (3) & (4) & (5) \\
\hline $10-7$. & When someone tells me how to do something in class, I learn it better. & (1) & $(2)$ & (3) & (4) & $(5)$ \\
\hline $10-8$. & When I do things in class, I learn better. & (1) & $(2)$ & (3) & (4) & (5) \\
\hline $10-9$. & I remember things I have heard in class better than things I have read. & (1) & (2) & (3) & (4) & (5) \\
\hline $10-10$. & When I read instructions, I remember them better. & (1) & $(2)$ & (3) & (4) & (5) \\
\hline $10-11$. & I learn more when I can make a model of something. & (1) & (2) & (3) & $(4)$ & (5) \\
\hline $10-12$. & I understand better when I read instructions. & (1) & $(2)$ & (3) & (4) & (5) \\
\hline $10-13$. & When I study alone, I remember things better. & (1) & (2) & (3) & (4) & (5) \\
\hline $10-14$. & I learn more when I make something for a class project. & (1) & $(2)$ & (3) & (4) & (5) \\
\hline $10-15$. & I enjoy learning in class by doing experiments. & (1) & $(2)$ & (3) & $(4)$ & $(5)$ \\
\hline $10-16$. & I learn better when I make drawings as I study. & (1) & (2) & (3) & (4) & (5) \\
\hline $10-17$. & I learn better in class when the teacher gives a lecture. & (1) & $(2)$ & (3) & $(4)$ & (5) \\
\hline $10-18$. & When I work alone, I learn better. & (1) & (2) & (3) & (4) & (5) \\
\hline $10-19$. & I understand things better in class when I participate in role-playing. & (1) & 2 & (3) & 4 & (5) \\
\hline $10-20$. & I learn better in class when I listen to someone. & (1) & $(2)$ & (3) & (4) & (5) \\
\hline $10-21$. & I enjoy working on an assignment with two or three classmates. & (1) & $(2)$ & (3) & $(4)$ & $(5)$ \\
\hline $10-22$. & When I build something, I remember what I have learned better. & (1) & $(2)$ & (3) & $(4)$ & (5) \\
\hline $10-23$. & I prefer to study with others. & (1) & (2) & (3) & (4) & (5) \\
\hline $10-24$. & I learn better by reading than by listening to someone. & (1) & (2) & (3) & (4) & (5) \\
\hline $10-25$. & I enjoy making something for a class project. & (1) & (2) & (3) & (4) & (5) \\
\hline $10-26$. & I learn best in class when I can participate in related activities. & (1) & (2) & (3) & (4) & (5) \\
\hline $10-27$. & In class, I work better when I work alone. & (1) & (2) & (3) & (4) & (5) \\
\hline $10-28$. & I prefer working on projects by myself. & (1) & (2) & (3) & (4) & (5) \\
\hline $10-29$. & I learn more by reading textbooks than by listening to lectures. & (1) & (2) & (3) & (4) & (5) \\
\hline $10-30$. & I prefer to work by myself. & (1) & (2) & (3) & (4) & (5) \\
\hline
\end{tabular}

* Questions 10-1 to 10-30 are designed by Joy Reid. 


\section{NOTES}

